
Revue Revue de l'histoire des religions
de I'histoire des religions
Judaïsme / christianisme : syncrétismes, antinomies, dissonances

\title{
Anne MASSONI, La Collégiale Saint-Germain l'Auxerrois de Paris (1380-1510)
}

Préface de Philippe conTAMINE. Limoges, Presses Universitaires de Limoges (« Histoire. Trajectoires »), 2009, 685 p., $24 \mathrm{~cm}, 30 €$, ISBN 978-2-84287-480-3

\section{Bénédicte Sère}

\section{(2) OpenEdition}

Édition électronique

URL : http://journals.openedition.org/rhr/7868

DOI : $10.4000 /$ rhr.7868

ISSN : 2105-2573

Éditeur

Armand Colin

\section{Édition imprimée}

Date de publication : 1 mars 2012

Pagination : 141-143

ISSN : 0035-1423

\section{Référence électronique}

Bénédicte Sère, "Anne mAsson, La Collégiale Saint-Germain l'Auxerrois de Paris (1380-1510) », Revue de

I'histoire des religions [En ligne], 1 | 2012, mis en ligne le 04 avril 2012, consulté le 22 septembre 2020. URL : http://journals.openedition.org/rhr/7868 ; DOI : https://doi.org/10.4000/rhr.7868

Ce document a été généré automatiquement le 22 septembre 2020.

Tous droits réservés 


\section{Anne MASSONI, La Collégiale Saint- Germain l'Auxerrois de Paris (1380-1510)}

Préface de Philippe conTAMINE. Limoges, Presses Universitaires de Limoges (« Histoire. Trajectoires »), 2009, 685 p., $24 \mathrm{~cm}, 30 €$, ISBN 978-2-84287-480-3

Bénédicte Sère

\section{RÉFÉRENCE}

Anne MASSONI, La Collégiale Saint-Germain l'Auxerrois de Paris (1380-1510). Préface de Philippe conTAmine. Limoges, Presses Universitaires de Limoges (« Histoire.

Trajectoires »), 2009, 685 p., 24 cm, $30 €$, ISBN 978-2-84287-480-3.

1 L'étude magistrale d'Anne Massoni met à la disposition des historiens une synthèse exhaustive sur la collégiale Saint-Germain l'Auxerrois à Paris de 1380 à 1510, synthèse qui permet de mieux appréhender la spécificité et la raison d'être de ce type d'église, la collégiale, dans le corps de la hiérarchie ecclésiale du temps mais aussi au cœur du tissu urbain de la capitale. En cette fin mouvementée du Moyen Âge, en effet, Saint-Germain l'Auxerrois s'impose à Paris comme l'établissement le plus prestigieux de la rive droite mais aussi comme le relais fondamental entre la cathédrale de Notre-Dame et les autres églises parisiennes. Le chapitre collégial, lui-même entouré d'une communauté de vicaires, clercs et chapelains, est institutionnellement doublé d'un clergé paroissial. Autrement dit, la collégiale est aussi cette immense paroisse de plus de sept mille úmes au $\mathrm{XV}^{\mathrm{e}}$ siècle. D'où la complexité institutionnelle de ce corps ecclésiastique dont Anne Massoni a retracé avec clarté la superposition des mécanismes mais aussi les tensions et les conflits liés aux emboîtements de prérogatives, de fonctions et de juridictions.

2 En trois temps, l'auteur présente la collégiale. Dans la première partie, c'est le visage institutionnel de cette communitas cléricale qui fait l'objet des huit premiers chapitres. 
Avec précision, l'auteur distingue les deux corps qui la composent : les chanoines d'une part (quatorze exactement), avec le doyen à leur tête, qui siègent en chapitre et gardent la main haute sur les décisions et le devenir de la collégiale; le reste de la communauté cléricale, non-canoniale, d'autre part, formé des vicaires, des chapelains, des bénéficiaires de tout type, des clercs inférieurs... Entre les deux corps surgissent des tensions, s'instaure une stricte hiérarchisation, mais se construit aussi une cohésion de plus en plus grande au fil des siècles. Chacun des deux corps possède ses représentants (les procureurs), ses officiers, ses "distributeurs", son budget et ses revenus. Tous pourtant, environ 40 à 50 personnes, se retrouvent chaque jour au chœur pour $\mathrm{y}$ « faire corps » tant il est vrai que la fonction centrale de la collégiale reste la célébration de la liturgie, chorale et obituaire, pour le salut de tous et la louange de Dieu. Telle est la pratique collégiale: une manière d'être au monde qui puise ses mœurs dans le monde monastique sans jamais pourtant se retrancher du monde ni le fuir puisque c'est au cœur des fidèles de ce quartier parisien que l'office est célébré quotidiennement.

Une seconde partie s'attache à "l'épaisseur humaine de la communauté »: l'étude emprunte aux méthodes prosopographiques pour scruter les hommes - 159 clercs répertoriés dans les registres capitulaires de 1382 à 1510 - qui se meuvent dans l'espace collégial. Sont alors retracés, pour une meilleure approche des profils cléricaux du temps, les origines sociales et géographiques des personnalités présentes, leur formation intellectuelle, leur carrière ecclésiastique et civile mais aussi leurs orientations voire leurs choix politiques en cette période de guerre civile et de Grand Schisme, au cours de laquelle les soustractions d'obédience ponctuent la vie interne de l'Église de France, enfin leurs réseaux et leurs solidarités. De la minutie de cet exemple, les conclusions permettront des généralisations qui redresseront certains stéréotypes sur l'image du chanoine de la fin du Moyen Âge : les chanoines et chapelains forment un clergé de plus en plus qualifié - notamment en droit - résidant à $89 \%$ - même si le canonicat de Saint-Germain peut représenter une étape prestigieuse dans une brillante carrière -, lié par de multiples réseaux particulièrement dans l'administration royale, soucieux de la gestion d'un patrimoine dans une pratique du bien commun. Par sa formation universitaire et son insertion dans les réseaux du pouvoir, le chanoine de Saint-Germain l'Auxerrois fait le lien entre la rive droite et la rive gauche de la capitale, sorte d'« intellectuel dans un quartier d'affaires» (p. 269). Personnage notable, il fait partie de l'élite du clergé parisien et les fidèles qui l'approchent n'y sont pas insensibles.

4 La dernière partie enfin montre l'insertion de la communauté dans la société civile ainsi que ses relations hors de l'église. Avec une technicité particulièrement maîtrisée, Anne Massoni montre surtout comment la collégiale dans son fonctionnement se double d'une fonction paroissiale. En effet, les clercs du chœur ont fait le choix de vivre dans le siècle et fréquentent au quotidien les paroissiens du quartier, ce qui confère à la collégiale un statut unique dans Paris, différent de celui du chapitre cathédral de Notre-Dame mais aussi de celui de n'importe quelle autre paroisse. Le curé, plus volontiers appelé " vicaire paroissial », est nommé par le doyen, resté " curé primitif ", et le chapitre : il en est l'émanation pour le service des fidèles, aidé lui-même par un clergé auxiliaire. Ce qu'il faut bien comprendre, c'est que le chapitre canonial n'est pas une structure parasite s'imposant à un clergé paroissial originel. Il est constitutif de l'encadrement paroissial même si, pour cette époque, les rôles sont clairement répartis entre les deux clergés et les oppositions ou conflits inévitables. Puis sont étudiés les liens de la collégiale avec la fabrique, puissant organe de décision également, qui ne 
dépend pas du chapitre; avec l'ensemble du quartier canonial où sont sises des écoles élémentaires ; avec l'évêque de Paris enfin. Bref, c'est une véritable emprise sur la rive droite qu'exerce la collégiale Saint-Germain l'Auxerrois, sans concurrence avec la cathédrale, mais qui l'érige dans une place décisive au sein du tissu religieux de Paris.

5 La force de cette étude s'origine foncièrement dans la composition du corpus documentaire. Si l'auteur peut rendre compte avec autant de rigueur et de minutie, non seulement des mécanismes institutionnels, mais tout autant des hommes qui les traversent, c'est parce qu'elle a su croiser les fonds issus des registres capitulaires et des archives ecclésiastiques (séries L, LL et S), mais aussi les sources pontificales, registres de lettres et suppliques des papes (de Clément VII à Jules II). Archives locales et archives pontificales ont permis d'articuler des approches complémentaires et d'insuffler à l'histoire institutionnelle classique la dimension humaine qui la fait vivre : au fil des pages, un monde canonial et clérical prend corps sous nos yeux et se meut dans les allées de son église collégiale. Au cours des liturgies et dans le quotidien de leurs activités, leurs voix montent jusqu'à nous pour redire leurs prières, leur autorité jalouse, leurs décisions capitulaires, leurs contentieux, leurs droits et leurs appels, leurs idéaux et leurs aspirations.

\section{AUTEURS}

\section{BÉNÉDICTE SÈRE}

Université Paris Ouest - Nanterre La Défense. 